4. The chlorine reacts primarily with the ammonia. It reacts only to a trifling extent, or not at all, with the solid ammonium chloride which is formed.

URBANA, ILA.

[CONTRIBUTION FROM THE CHEMICAL LABORATORY OF THE UNYVERSITY OF ILLINOIS.]

\title{
THE REACTION BETWEEN CHLORINE AND AMMONIA. III. PROBABLE FORMATION OF TRICHLORO- AMMONIUM CHLORIDE.
}

BX WILLIAM ALBERT NOYES.

Received Juiy 12, 1920.

With the exception of the experiments described in the preceding paper, and those of Bray and Dowel1 ${ }^{1}$ and of Noyes and Lyon, ${ }^{2}$ nitrogen trichloride seems always to have been prepared by the action of chlorine; ${ }^{3}$ a hypochlorite, ${ }^{4}$ or hypochlorous acid, ${ }^{5}$ on ammonium chloride. Even those who have used chlorine have considered that hypochlorous acid is at first formed and that this acid then reacts with the ammonium salt. ${ }^{6}$ The results described in the preceding paper demonstrate that nitrogen trichloride may be prepared by the direct interaction of chlorine and ammonia, in the absence of water. Experiments to be described in this paper show that nitrogen trichloride reacts quantitatively with hydrochloric acid, in the absence of water, giving ammonium chloride and chlorine. Also, when hydrogen chloride is passed into a solution of zitrogen trichloride in carbon tetrachloride ${ }^{7}$ an immediate precipitation of ammonium chloride is caused.

In the light of these results it seems clear that the decomposition of nitrogen trichloride by hydrochloric acid is not an hydrolysis, under the conditions just described.

The most rational explanation of the formation of nitrogen trichloride from anmonium chloride seems to be that chlorine adds itself to ammonia, which is doubtless present in small amounts from the dissociation of the ammonitm chloride to ammonia and hydrochloric acid. The chloro-

. Bray and Dowell, This Journal, 39, 905 (1917).

"Noyes and Lyon, ibid., 23, 460 (rgor).

"Gattermatn, Ber., 2I, 75I (r888); Hentschel, ibid., 30, I792 (I897); Chapman and Vodden, $J$. Chem. Soc., 95, I4 (1909).

"Hentschel, Ber., 30, I434 (1897).

'Balard, Ann. chim. phys., [2] 57, 258 (I894); Hentschel, Ber., 30, I792 (1897); Dowell and Bray, Thrs JournaL, 39, 896 ( $\mathrm{x}^{\mathrm{i}} \mathrm{i} 7$ ). Balard speaks of using other ammonium salts but gives no details. He also used a solution of ammonia.

- Seliwanoff, Ber., 27, ror 2; Chapman and Vodden, loc, cit.

This experiment was suggested by Professor Washburn in a conversation in which the author expressed the opinion that the decomposition of nitrogen trichloride by conc. hydrochloric acid is not an hydrolysis. 
ammonium chloride, $\mathrm{NH}_{3} \mathrm{Cl}^{+} \mathrm{Cl}^{-}$-, formed in this manner, would dissociate easily into chloro-amine, ${ }^{1} \mathrm{NH}_{2} \mathrm{Cl}$, and hydrochloric acid. The chloroamine would then add another mol of chiorine, giving dichloro-ammonium chloride, $\mathrm{NH}_{2} \mathrm{Cl}_{2}+\mathrm{Cl}$.- A repetition of the dissociation and addition and a third dissociation would give nitrogen trichloride.

Seliwanoff, Chapman and Vodden, and others, have shown, qualitatively, that the interaction of nitrogen trichloride and hydrochloric acid gives anmonium chloride and chlorine, but they have considered the decomposition as primarily an hydrolysis of the trichloride. Seliwanoff states that the trichloride is scarcely affected by sulfuric acid, and he explains the different effect of the hydrochloric acid by saying that the hypochlorous acid formed by the hydrolysis reacts with the hydrochloric acid to give free chlorine. He fails to explain why the free chlorine does not react with the ammonium chloride in the solution to give nitrogen trichloride again. In the experiments described below, it was shown that by shaking a solution of nitrogen trickloride with conc. hydrochloric acid more than $99 \%$ of the nitrogen of the trichloride passed into the aqueous phase, as anmonium chloride. On shaking a similar solution with sulf uric acid ( $\mathrm{I}$ cc. $=0.6 \mathrm{~g}$. of $\mathrm{H}_{2} \mathrm{SO}_{4}$ ) only a trace of the nitrogen was converted into an ammonium salt.

When a similar solution of nitrogen trichloride was shaken with a saturated solution of salt to which $5 \%$ by volume of conc. hydrochloric acid was added only a very small amount of the trichloride was converted to ammonium chloride.

It seems difficult to explain these results on the supposition that the decomposition is an hydrolysis. ${ }^{2}$ They are easily explained on the basis that nitrogen trichloride is, in reality, trichloro-amine and that a mol of chlorine may separate into one positive and one negative chlorine atom. On this supposition nitrogen trichloride would add a mol of hydrogen chloride exactly as ammonia does. The resuiting compound, trichloro-ammonium chloride, $\mathrm{NCl}_{3}+\mathrm{H}^{+}+\mathrm{Cl}^{-}$, might dissociate either by loss of hydrogen chloride or by loss of one positive and one negative chlorine atom as free chlorine. The dissociation to nitrogen trichloride and hydrogen chloride would occur in the presence of dil. hydrochloric acid, or of the acid salt solution or of sulfuric acid as mentioned in the last paragraph, jusi as

${ }^{2}$ Raschig, Chem. Ztg, 3I, 926 (1907).

2 Professor Bray, who has been kind enough to read this paper, points out that the possibility of hydrolysis, as a rapid reaction, is not excluded for these cases when water is present. In the presence of water the mechanism of the reaction may be different from that of the reaction in the absence of water. In the light of the experiment described here, he does not, however, take the ground that hydrolysis is the more likely mechanism when water is present. Even in rgry (loc.cil., p. 905, footnote 2) he stated that we had no means of deciding. He further states that the new results of this paper greatly weaken the case for hydrolysis. 
some organic amines form salts only in the presence of concentrated acids. In the presence of conc. hydrochloric acid, however, the tendency wottd be to dissociate to dichloro-arnine, $\mathrm{NHCl}_{2}$, and free chlorine and a repetition of this process would give ammonimm chloride and chlorine as the end-products.

It seems probable that the action of hypochlorous acid on ammonitum salts is similar to that of chlorine, as explained above. Hypochlorous acid would add itself to ammonia, giving chloro-ammonium hydroxide, $\mathrm{NH}_{3} \mathrm{Cl}+\mathrm{OH}^{-}$, exactly as it adds to ethylene to give ethylene chlorohydrin, $\mathrm{CH}_{2} \mathrm{Cl}_{1} \mathrm{CH}_{2} \mathrm{OH}$. Chloro-ammonium hydroxide would, of course, dissociate to chloro-amine, $\mathrm{NH}_{2} \mathrm{Cl}$, and water, and repetitions of the process would give nitrogen trichloride.

Action of Chlorine on Ammonium Salts. - The experiments reported in the following table were carried out, partly by shaking a solution of chlorine in carbon tetrachloride, of known concentration, with solutions of amrononium salts (Expts. I-16) and partly by passing chlorine into a layer of carbon tetrachloride beneath a solution of an ammonium salt. The solutions were shaken from one to five minutes in most cases, equilibrium being reached rather quickly. The nitrogen and total chlorine were determined in the carbon tetrachloride solution in most cases, by reduction with sodiun sulfite, as described by Bray and Dowell. ${ }^{1}$ In some of the Iater experiments, however, the nitrogen of the chlorides of nitrogen was determined by shaking the carbon tetrachloride solution with about an equal volume of conc. hydrochloric acid. This method gives a practically quantitative conversion of the chlorides of nitrogen to ammonium chloride with less danger of loss of nitrogen than when sodium sulfite is used. In a number of cases higher results were found with the use of hydrochloric acid than with the use of sodium sulfite. This may be particularly true when chloro-amine or dichloro-amine is present, but that has not been fully demonstrated.

In every case where the aqueous solution was examined at once after separating it from the carbon tetrachloride it was found to contain some substance which would liberate iodine from potassium iodide. The amount of lodine liberated was determined by titration with sodium thiosulfate and the results calculated on the supposition that the oxidizing compound was chloro-amine, $\mathrm{NH}_{2} \mathrm{Cl}$. As yet it has not been shown, however, whether the compound present was chloro-amine, dichloroamine or nitrogen trichloride.

In the table which follows, the results are calculated on the basis of the mols of ammonium ( $\mathrm{NH}_{4}$ ) reacting with 6 atoms of chlorine. It gives the number of mols of each product formed, also the ratio of chlorine to nitrogen in the carbon tetrachloride solution.

Loc. cit. 
TABLE I.

Results Calculated to 6 Atoms of Chlorine.

\begin{tabular}{|c|c|c|c|c|c|c|c|c|c|}
\hline xpt & & $\begin{array}{l}\text { Nolar } \\
\text { cone. } \\
\text { NH4. }\end{array}$ & $\begin{array}{l}\text { Atomic } \\
\text { conce. } \\
\text { Cl. }\end{array}$ & $\begin{array}{l}\text { Mols } \\
\text { NHI. }\end{array}$ & $\begin{array}{l}\mathrm{Mols} \\
\mathrm{NCl}_{3 .}\end{array}$ & $\begin{array}{c}\text { Mols } \\
\text { NH/ re- } \\
\text { covered. }\end{array}$ & $\begin{array}{l}\text { Atoms } \\
N \\
\text { lost. }\end{array}$ & $\begin{array}{l}\text { Mols } \\
\mathrm{NH}_{2} \mathrm{Cl}\end{array}$ & $\begin{array}{c}\mathrm{Cl}: \mathrm{N} \\
\text { in } \mathrm{CC} l_{s} \\
\text { solution }\end{array}$ \\
\hline I & $\mathrm{NH}_{4} \mathrm{Cl}$. & I. $O$ & 0.46 & 0.79 & 0.35 & $0.4 \mathrm{I}$ & 0.04 & . & II. 9 \\
\hline 2 & $\mathrm{NH}_{4} \mathrm{Cl}$ & 0.1 & 0.59 & 0.98 & 0.74 & 0.09 & 0.07 & 0.08 & 5.8 \\
\hline 3 & $\mathrm{NH}_{4} \mathrm{Cl}$ & $0 . \mathrm{I}$ & 59 & I. 96 & $3.7 \mathrm{I}$ & 0.8 & 0.37 & 0.04 & $5 . \mathrm{I}$ \\
\hline 4 & $\mathrm{NH}_{4} \mathrm{Cl}$. & I.O & .59 & I. 56 & . I 4 & I. 24 & 0.17 & $\therefore$ & $33 \cdot 5$ \\
\hline 5 & $\mathrm{NH}_{4} \mathrm{C}$ & O.I & o. 35 & I. 03 & $0.8 I$ & & 0.01 & 0.03 & 3.88 \\
\hline 6 & $N$ & O.I & 9 & 0.95 & 59 & 0.25 & 0.03 & 0.08 & 5.96 \\
\hline 7 & $\mathrm{NH}$ & $0 . r$ & .4 & I. C & o. & o. & O. II & 0.06 & 7.03 \\
\hline 8 & $\mathrm{Nl}$ & $0 . x$ & 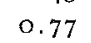 & 0 & 0.75 & & O.II & 0.0 & 4.09 \\
\hline 9 & & 0.0 & o & o. & .7 & o. & 0.09 & 0.0 & 3.84 \\
\hline IO & & 0.1 & .56 & 3.06 & .94 & 2.0 & . . & 0.08 & 2.97 \\
\hline$I I$ & $N$ & $0 . I$ & 0.27 & 1.00 & 0.66 & 0.2 & $0 . I I$ & $0.0 \mathrm{r}$ & 3.93 \\
\hline I2 & $\mathrm{NI}$ & O. I & 0.3 & 2.80 & 0.92 & I. & . & 0.06 & 2.74 \\
\hline 13 & $\mathrm{NH}_{4}$ & O.I & 0.5 & 2.92 & .98 & & 0.15 & 0.09 & 2.52 \\
\hline I4 & $\mathrm{NH}_{4}$ & 0.1 & & $\mathrm{r}$ & .8 & & $0.0 x$ & $\ldots$ & $3 \cdot 92$ \\
\hline 15 & $\mathrm{NH}_{4}$ & $0 . \mathrm{I}$ & 0 & 0.9 & .70 & 0. & 0.17 & . & 6.00 \\
\hline 6 & (NH & 2.0 & 4 & 3. & 0.8 & & 0.15 & 0.01 & 3.06 \\
\hline 7 & $(\mathrm{NF}$ & 0.2 & & 3 & 0.85 & & 0.16 & 0.09 & $3 \cdot 13$ \\
\hline 18 & $\mathrm{NH}$ & 2.0 & I. 60 & 3 & 0.78 & 2. & 0.24 & 0.10 & .70 \\
\hline Ig & & 2.0 & & & . & 2.19 & O.II & $0.0 \mathrm{~T}$ & 2.82 \\
\hline 20 & & O.I & I. $6 \mathrm{~T}$ & 2.86 & 0.90 & x. 73 & 0.05 & 0.18 & 3.06 \\
\hline $2 I$ & & 2.0 & . & 8.4 & 0.87 & 7.22 & 0.26 & 0.05 & $3 \cdot 55$ \\
\hline 22 & $(\mathrm{NF}$ & 2.0 & . & 8.4 & 0.92 & & 0.26 & 0.05 & 3.21 \\
\hline 23 & $\left(\mathrm{NH}_{4}\right)_{2} \mathrm{SO}_{4}$ & 2.0 & .. & 7.43 & 0.87 & $6.2 \mathrm{I}$ & 9.29 & 0.05 & $3.5 \mathrm{I}$ \\
\hline
\end{tabular}

These results seem to justify the following conclusions.

When a normal solution of ammonium chloride is treated with 6 atoms of chlorine for one mol of ammonium, the hydrochloric acid formed becomes so concentrated as to interfere seriously with the formation of nitrogen trichloride (Expts. $I$ and 4 ). For the theoretical reaction the hydrochloric acid would become $4 N$.

With a o.I $N$ solution of ammonium chloride the per cent. of nitrogen trichloride formed is much larger.

In all cases, an appreciable amount of a chloro-amine remains in the aqueous solutiou. In proportion to the chlorine used this is nuch larger in the dilute solution.

Solutions of soditum ammonium phosphate and of ammonium sulfate give a larger per cent. of nitrogen trichloride, in proportion to the chlorine used, than solutions of ammonium chloride do. This is evidently because the resulting solutions contain a lower concentration of hydrochloric acid.

In Expts. I3, I4 and 20 the ratio of nitrogen to chlorine is considerably below 3 to $x$ in the carbon tetrachloride solution. Gattermann ${ }^{3}$ and

"Gattermann, Ber, 2I, 75I (I 888). 
Hentsche $1^{1}$ have reported similar ratios when nitrogen trichloride is prepared by the action of chlorine on ammonium chloride. The experiments of Hentschel ${ }^{2}$ and of Dowell and Bray $^{3}$ indicate that the conversion to the trichloride is complete when hydrochlorous acid is used. The low ratio must, of course, be due to the presence of some chloro-amine, $\mathrm{NH}_{2} \mathrm{Cl}$, or dichloro-amine, $\mathrm{NHCl}_{2}$. The explanation of the formation of the chloro-amines and nitrogen trichloride as due to the addition of chlorine to ammonia and splitting off of hydrogen chloride in the one case and to the addition of hypochlorous acid and splitting off of water in the other agrees excellently with these results. In the 2 equilibria,

$$
\mathrm{NH}_{2} \mathrm{Cl}+\mathrm{Cl}-\mathrm{NH}_{2} \mathrm{Cl}+\mathrm{HCl} \text {, }
$$

and

$$
\mathrm{NH}_{2} \mathrm{Cl}+\mathrm{OH}^{-} \longleftrightarrow \mathrm{NH}_{2} \mathrm{Cl}+\mathrm{HOH} \text {, }
$$

it is evident that the equilibrium would be much farther toward the formation of the chloro-amine in the second case than in the first. Whether the substance present in the carbon tetrachloride solution, or in the aqueous solution, is chloro-amine, dichloro-amine, nitrogen trichloride, or a mixture, when chlorine is used, has not been determined. Experiments on this point will be undertaken later.

There is usually a considerable loss of nitrogen. The results are somewhat erratic, but, in general, the loss is greater when the ammonium salt is in excess. It also seems to be greater in the phosphate than in the ammonium chloride solutions. This is probably connected with the lower hydrogen ion concentration in the phosphate solution.

Action of Hydrogen Chloride on Nitrogen Trichloride.-The precipitation of ammonium chloride when hydrogen chloride is passed into a solution of the trichloride in carbon tetrachloride has been mentioned above.

In another experiment nitrogen trichloride was prepared by passing chlorine into a solution of ammonium sulfate contained in an inclined bulb connected with a serpentine tube at the top, which was in turn connected both with an exit for the gases and a return tube which carried the liquid pushed forward by the gas back to the bottom of the bulb. The whole was surrounded with a wooden box to protect the trichloride from the light and as a precaution in case of explosion. The chlorine was almost completely absorbed by the ammonium sulfate solution and the nitrogen trichloride collected in a globule in the lower part of the bulb. A current of air was then passed through the bulb and the mixture of air and vapor of the trichloride was passed through a wash bottle containing conc. sulfuric acid to dry it and then through a $U$-tube surrounded by a

${ }^{1}$ Hentschel, Ber., 30, I792 (1897).

2 Hentschel, ibid., 30, 2642 (I897).

a Iris JOURNAL, 39, 896 (I9I7). 
freezing mixture. This method of separating pure nitrogen trichloride without the use of a solvent is much easier of manipulation and saier than the method described by Gattermann.'

After about $0.37 \mathrm{~g}$. of the trichloride (calculated from the ammonium chloride formed by its decomposition) had collected in the U-tube, dry hydrogen chloride was passed through the tube. The chlorine liberated was passed through a small coil containing water to remove the excess of acid and into a solution of potassium iodide. There was left in the U-tube $3.01 \mathrm{mg}$. mols of solid ammonium chloride, $0.028 \mathrm{mg}$. mols of ammonium were found in the potassium iodide solution and $18.95 \mathrm{mg}$. of iodine was liberated by the chlorine, as determined by titration with sodium thiosulfate. The ratio is one mol of ammonium chloride to 6.075 atoms of free chlorine. The nitrogen trichloride had been converted quantitatively into ammonium chloride and free chlorine.

In another experiment, performed on a hot day, the product condensed in the U-tube was found to boil below $30^{\circ}$ and the ratio between the mols of ammonium chloride and atoms of chlorine obtained by treating it with hydrogen chloride was very nearly $\mathrm{I}: 4$. This may, possibly, indicate that the product was dichloro-amine, $\mathrm{NHCl}_{2}$. This will be investigated further.

Sixteen g. of a solution of nitrogen trichloride in carbon tetrachloride gave I. I $73 \mathrm{mg}$. mols of ammonium chloride on shaking once with is $\mathrm{cc}$. of conc. hydrochloric acid. Sixteen $g$. of the same solution gave 1.185 mg. mols of ammonia when treated with $25 \mathrm{cc}$. of a sodium sulfite solution. In another experiment $20.2 \mathrm{~g}$. of a solution of nitrogen trichloride in carbon tetrachloride gave $1.87 \mathrm{mg}$. mols of ammonium chloride when shaken with ro $\mathrm{cc}$. of conc. hydrochloric acid, while the carbon tetrachloride solution containing chlorine which was separated from the acid solution. gave only $0.004 \mathrm{mg}$. mols of ammonia by reduction with sodium sulfite. In other words, $99.8 \%$ of the original trichloride had been converted to ammonium chloride. In a number of comparative determinations, treatment of nitrogen trichloride solutions in carbon tetrachloride with conc. hydrochloric acid gave either the same amount of ammonia or a larger amount than when the same solutions were reduced with sodium sulfite.

\section{Summary.}

r. Dry hydrogen chloride converts nitrogen trichloride quantitatively to ammonitum chloride. The reaction may occur either with a solution of the trichloride in carbon tetrachloride or without any solvent. This demonstrates that the decomposition is not an hydrolysis, in the absence of water, and probably not an hydrolysis in the presence of water.

2. It seems probable that the action consists primarily in the formation of trichloro-ammonium chloride, $\mathrm{NCl}_{3} \mathrm{HCl}$, followed by the loss of

${ }^{1}$ Gattermann, Ber., 2I, 75 I (r888). 
an atom of positive chlorine combined with an atom of negative chlorine.

3. The formation of nitrogen trichloride by the action of chlorine on at ammonitum salt seems to be the reverse of the reaction just described. Anmonium sulfate is much more suitable than ammonium chloride for: the preparation of the trichloride.

4. Chloro-amine or dichloro-amine are formed, as well as nitrogen trichloride, when ammonium salts are treated with chlorine.

5. Treatment of an ammonium salt with hypochlorous acid is better than treatment with chlorine for the preparation of pure nitrogen trichloride free from other chloro-amines.

6. Nitrogen trichloride may be separated from a solution in which it is prepared by passing a current of air through the solution, drying the air and vapor of the trichloride with conc. sulfuric acid and condensing the trichloride in a $U$-tube surrounded with a freezing mixture.

Three of the most fundamental questions now before chemists for consideration are:

ז. Are all, or nearly all, reactions essentially ionic in character? When two atoms or radicals separate and recombine, is one of the atoms ustally positive and the other negative?

3. If the first question is answered in the affirmative, are the positive and negative character of atoms retained in compounds?

3. Is the simplest bond of union between two atoms due to one electron or two?

The experiments which have been described seem to throw some light on the first 2 questions. If the interpretation given is true, trichloroammonium chloride, $\mathrm{NCl}_{3} \mathrm{HCl}$, contains one chlorine atom which is bound to the nitrogen atom, or to the group, in an essentially different manner from the combination of the other 3 . This chlorine atom tends to separate from combination carrying an extra electron, while either of the other 3 chlorine atoms tends to separate from the nitrogen atom with the loss of an electron, i.e., as a positive atom. The negative chlorine atom may then combine with the positive atom to form free chlorine.

The experiments throw little or no light on the question whether in free chlorine one atom remains positive and the other negative, or as to whether the 2 atoms are bound by a single electron or by two. 